\title{
SHEET FLOW CAVES OF KILAUEA CALDERA, HAWAII COUNTY, HAWAII
}

\author{
William R. Halliday *
}

\begin{abstract}
Terminal lobes of sheet flows of pahoehoe lava sometimes form three-dimensional nests, initially separated by partitions consisting of accreted "skins" of each lobe. Melting breaks down these partitions, forming a uniform flow unit. In Kilauea Caldera we have found and mapped sizable drained cavities in low-slope sheet flows. Their general pattern includes three-dimensional nests, with partially melted septa evident in some examples. Christmas Cave is the most extensive found to date, with 632 meters surveyed on two levels. It is located at the lower end of an inflated sheet flow tongue which underwent local deflation as a result of drainage through the cave after its parameters were partially fixed. Small conduit remnants persist in its boundary ridges. The major part of the cave consists of wide, low nested chambers. Meltdown of such partitions is one of the few emplacement mechanisms of thermal erosion which may not involve any mechanical element. Additional caves in this caldera are being identified and studied.
\end{abstract}

Keywords: geomorphology, volcanic caves, speleogenesis, Hawaii

\section{INTRODUCTION}

The 1990's have been a decade of greatly increased understanding of emplacement of non-channelized pahoehoe basalt flows and the caves within them. Especially important are new concepts of emplacement of sheet flows resulting from studies at the flow front of Kilauea Volcano's current Puu Oo flows (Hon et al, 1994).

In such sheet flows, tube-fed lava advances in sequences rather than uniformly, "with lava constantly being flushed through the flow" (Hon et al, 1991) by hydrostatic pressure. The overall lengthening of such flow fields is a slower process than some have assumed previously. At the flow front, however, lava toes and other small breakouts are emitted quickly and their surfaces chill rapidly, forming "skins" which initially are quite thin but have significant tensile strength. Upstream hydraulic pressure causes especially liquid lava to be injected into flow lobes supplying these breakouts, as elsewhere in the flow field where peripheral resistance is comparatively low. At the flow front, this injection creates one of a stack of semicircular sheets, eventually one to a few meters thick, more or less across the entire flow. Within this stack of lava sheets, rounded injection masses sometimes form well-insulated three dimensional nests of fluid lava (Hon, Ken, personal communication, 1997). Each unit in these nests originally is separated from the others by thin partitions representing the apposed outer surface "skin" of each rounded mass. The tensile strength of these septa ultimately is destroyed by prolonged exposure to the intense heat in the interior of each unit, resulting in coalescence into a continuous liquid lava core beneath a single upper-crustal layer "with complete fluid connection between adjacent lobes" (Hon et al, 1994).

\footnotetext{
" Hawaii Speleological Survey, 6530 Cornwall Court - Nashville, TN USA 37025.
} 


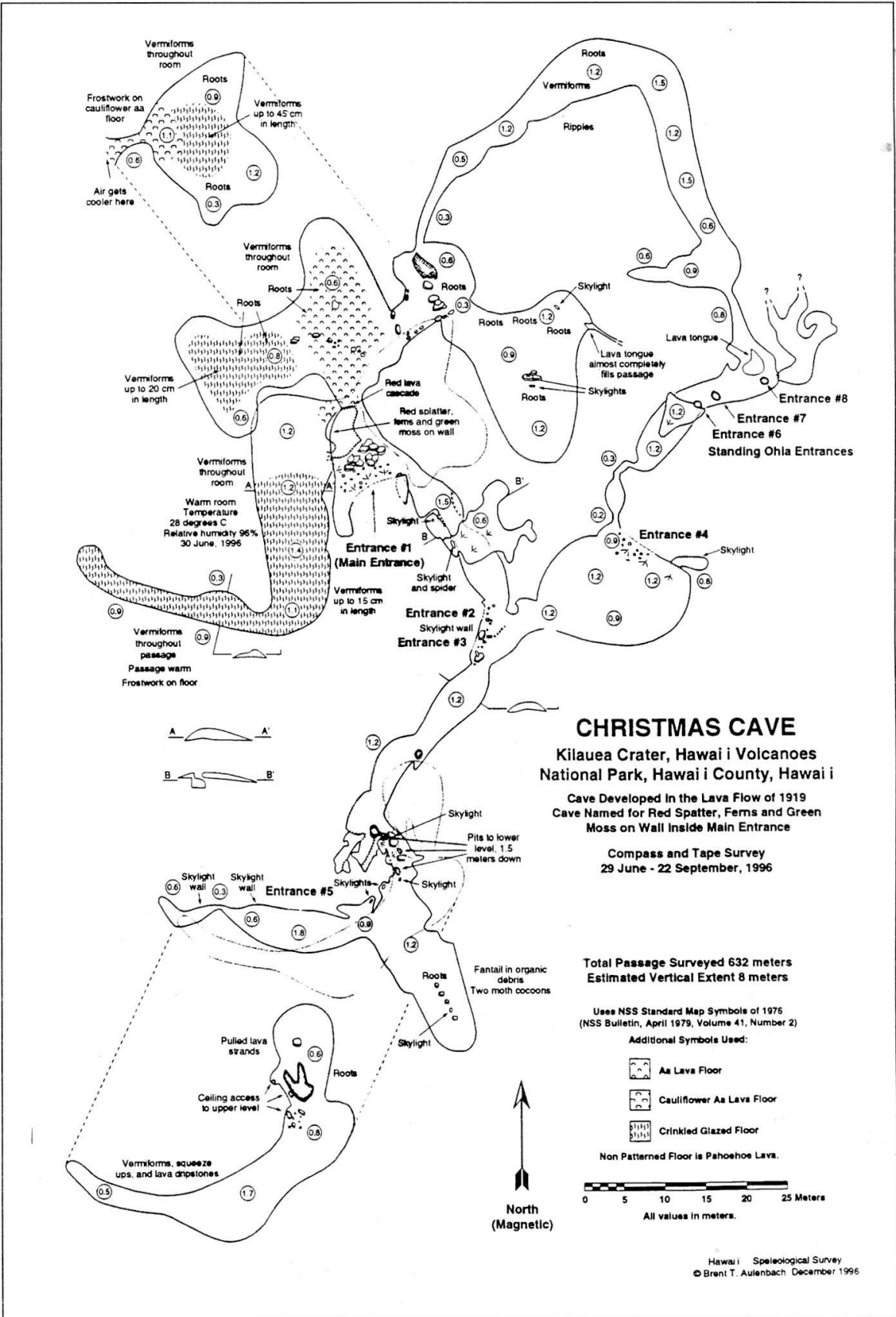

Fig. 1. Map of Christmas Cave, Kilauea Crater, Hawaii Volcanoes National Park, Hawaii County, Hawaii - Cave developed in the Lava Flow of 1919, Cave Named for Red Spatter, Ferns and Green Moss on Wall Inside Main Entrance Compass and Tape Survey, 29 June - 22 September, 1996. 


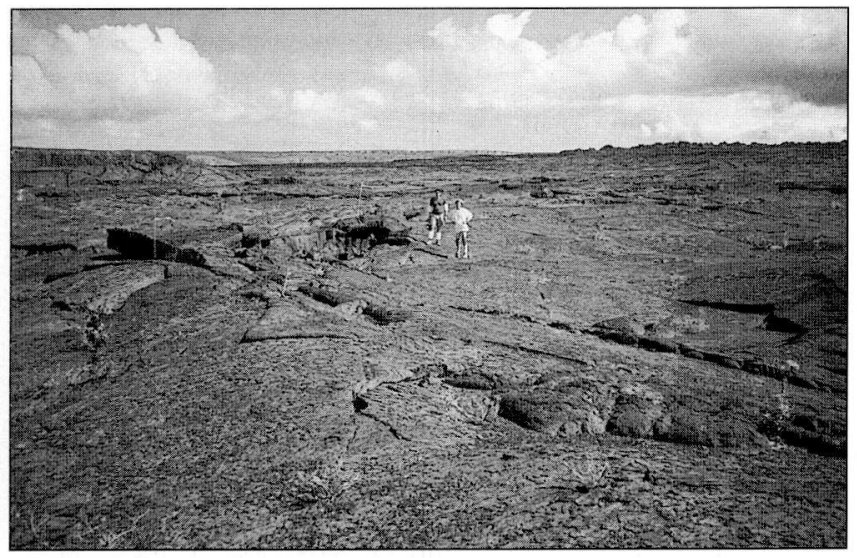

Fig. 2. The sinuous central depression of the deflated Christmas Cave lava tongue, with flagged poles (emplaced from the cave through "lightholes") marking the course of its east boundary ridge.

Fig. 3. East boundary ridge passage of Christmas Cave.
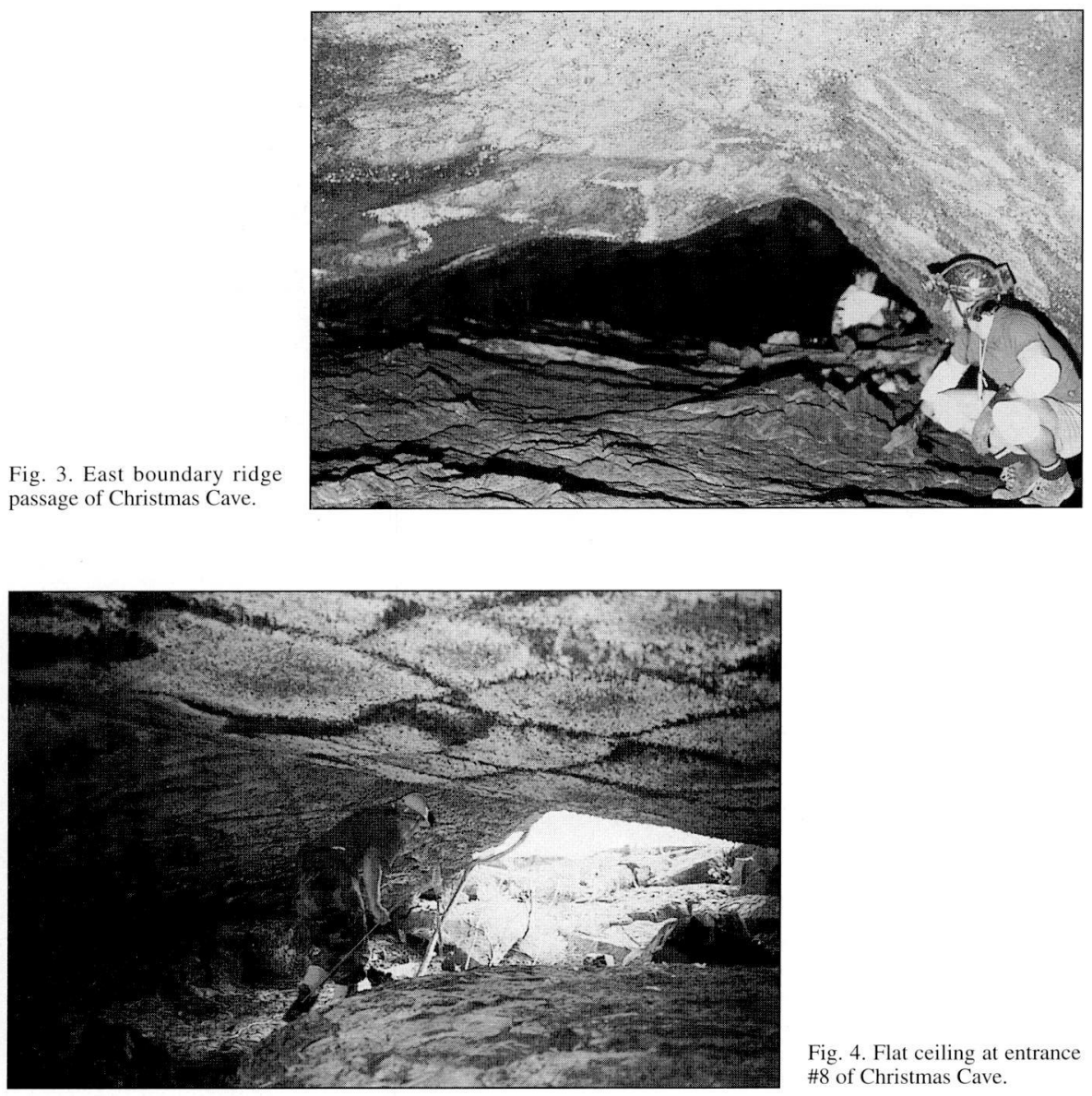

Fig. 4. Flat ceiling at entrance \#8 of Christmas Cave. 


\section{RING CAVE AND RINGLEADER CAVE} Kilauea Crater, Hawaii

Sisteco compasses and cloth tape

2 March 1996

Hawaii Speleological Survey

Revised $3 / 2 / 97$

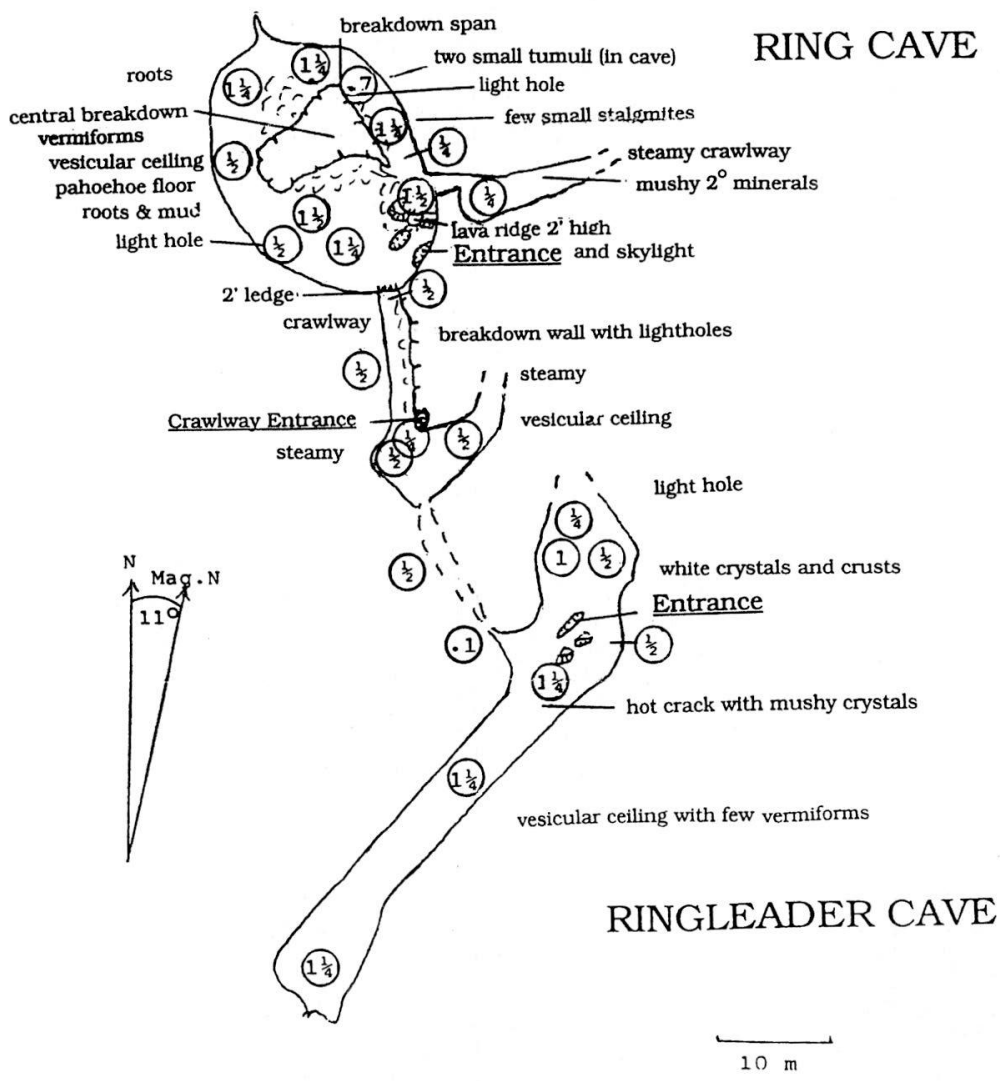

Fig. 5. Map of Ring Cave-Ringleader Cave complex, Kilauea Crater, Hawaii - Sisteco compasses and cloth tape, 2 March 1996, Hawaii. 


\section{CAVES FORMED BY DRAINAGE OF INJECTION MASSES}

In Kilauea Caldera we have found evidence of drainage of some of these injection masses prior to coalescence, producing interconnected cavernous chambers and passages with partial septa. To date, Christmas Cave is both the largest and most illustrative of these. We have surveyed 632 meters on two levels in this cave (Fig. 1). It is at the lower end of an inflated sheet flow lobe which underwent local deflation as a result of partial drainage after its surface features were partly fixed (Fig. 2). Well-defined boundary ridges remain on both sides of what now is a sinuous central depression terminating at the main entrance of the cave (here the crust was too solidified to sag). Small elongate remnants of the central conduit persist in both boundary ridges; much more extensively within the east ridge (Fig. 3). The remainder of the cave consists of wide, low nested chambers, two drain tubes (Fig. 4), and two additional boundary ridge passages in a lower flow unit presumably emplaced earlier (Fig. 1). Lower level passages exist in two separate sections of the cave. The nested chambers are 1 to $2 \mathrm{~m}$ high and up to 20 meters in diameter, on both levels. Remnants of the melted partitions are clearly visible in the cave and on the map.

Some of the drained flow lobe caves of Kilauea Caldera have a more complex origin. The Ring-Ringleader complex (Fig. 5) has three interconnected but dissimilar components. The Ring Cave section is a small drained lava rise or tumulus with central breakdown and an effluent crawlway. The Ringleader Cave section is a simple primitive-appearing tube within a flat-topped lava rise which ends by a gentle slope at the lower end of the cave (Fig. 6). It drained into (and possibly formed) a small adjacent lava tongue at a level 1-2 meters lower than the floor of Ringleader Cave, by way of a small hole which widened progressively downslope. This lava tongue deflated, draining into Ring Cave, $1 / 2-1$ meter still lower. This deflation left intact its upslope boundary ridge which contains a crawlway passage connecting Ring Cave and Ringleader Cave. It appears that these two caves originally were independent bodies of injected lava. The small hole draining Ringleader Cave may have been a hydrostatic breakout, but the widely patent opening between the main room of Ring Cave and the connecting crawlway appears to have been caused by a septum disruption.



Fig. 6. Looking south from main entrance of Ring Cave to its crawlway entrance (center), drained lava tongue (lower left) and entrance of Ringleader Cave (background). 
Meltdown of septa in these sheet flows is one of the very few emplacement mechanisms due to active melting: true thermal erosion which may have had no mechanical component. As more small caves are identified and studied in Kilauea Caldera, it is likely that much more will be learned about these and related processes.

\section{ACKNOWLEDGMENTS}

Olé Fulks merits special commendation as the discoverer of Christmas Cave. Ken Hon and Don Swanson independently confirmed the chambers of Christmas Cave as drained flow lobe cavities. Numerous members and cooperators of the Hawaii Grotto and the Hawaii Speleological Survey of the National Speleological Society provided essential field assistance. These studies were performed under permit by the National Park Service, facilitated by Superintendent Jim Martin and Cave Resource Specialist Bobby Camara of Hawaii Volcanoes National Park. My thanks to all.

\section{REFERENCES}

HON, KEN ET AL. 1994. Emplacement and inflation of pahoehoe sheet flows: observations and measurements of active lava flows on Kilauea Volcano, Hawaii. Geol. Soc. Amer. Bulletin, vol. 106, p. 351. 